\title{
Cholesterol Deficiency - new genetic defect transmitted to Polish Holstein-Friesian cattle
}

\author{
S. Kamiński, A. Ruść \\ University of Warmia and Mazury, Department of Animal Genetics, Oczapowskiego 5, 10-719 Olsztyn, Poland
}

\begin{abstract}
The aim of the study was to find out whether carriers of new genetic defect Cholesterol Deficiency (CD) occur in the population of Polish Holstein-Friesian bulls. Twenty seven bulls were included in the analysis. Bulls were selected as having in the pedigree known carrier of CD (Maughlin Storm CANM000005457798). All bulls were diagnosed by the test described by Menzi et al. (2016) by using allele-specific PCR. Among 27 bulls, 9 new CD carriers were found. Our results show that causal mutation for $\mathrm{CD}$ is already transmitted to Polish Holstein-Friesian cattle. The results are sufficient ground to take practical action in order to avoid further spreading of mutation causing CD.
\end{abstract}

Key words: bull, genetic defect, carrier, Cholesterol Deficiency

\section{Introduction}

Cholesterol Deficiency (CD) is a new autosomal monogenic recessive defect in Holstein cattle (OMIA 001965-9913). Calves being recessive homozygotes die within a period of days to months after birth as a consequence of the onset of idiopathic diarrhea (Kipp et al. 2015). A combined approach of a genome-wide association study (GWAS) and homozygosity mapping revealed a $\sim 2.7 \mathrm{Mb}$ disease associated haplotype on BTA 11 (Kipp et al. 2015). The disease associated haplotype traces to the Holstein sire Maughlin Storm born in 1991 (VanRaden and Null 2015). Menzi et al. (2016) re-sequenced the entire genome of an affected calf and a healthy partially inbred male carrying one copy of the critical $2.24-\mathrm{Mb}$ segment and detected a causal mutation $-1.3 \mathrm{~kb}$ insertion of a transposable LTR element (ERV2-1) located in the coding sequence of the apolipoprotein B (APOB) gene. This insertion generated premature stop codon resulting in a truncation of the APOB protein to less than 140 amino acids. The $1.3 \mathrm{~kb}$ insertion was confirmed by Schütz et al. (2016), who reported that the LTR element was inserted into exon 5 of the APOB gene (at BTA11:77,959kb) and is flanked by $6 \mathrm{bp}$ target site duplications typical to insertions mediated by retroviral integrases. APOB is an essential compound of chylomicrons and low-density lipoproteins. It seems then that the mutation represents a loss-of-function mutation similar to autosomal recessive inherited familial hypobetali-poproteinemia-1 (FHBL1) in humans (Young et al. 1988). Gross et al. (2016) reported that the causal mutation for CD affects lipid metabolism, steroid biosynthesis and cell membrane function in homozygous as well as heterozygous carriers and may result in unspecific symptoms like reduced fertility, growth, and health. The rapid exchange of genetic material by means of artificial insemination,

Correspondence to: S. Kamiński, e-mail: stachel@uwm.edu.pl 


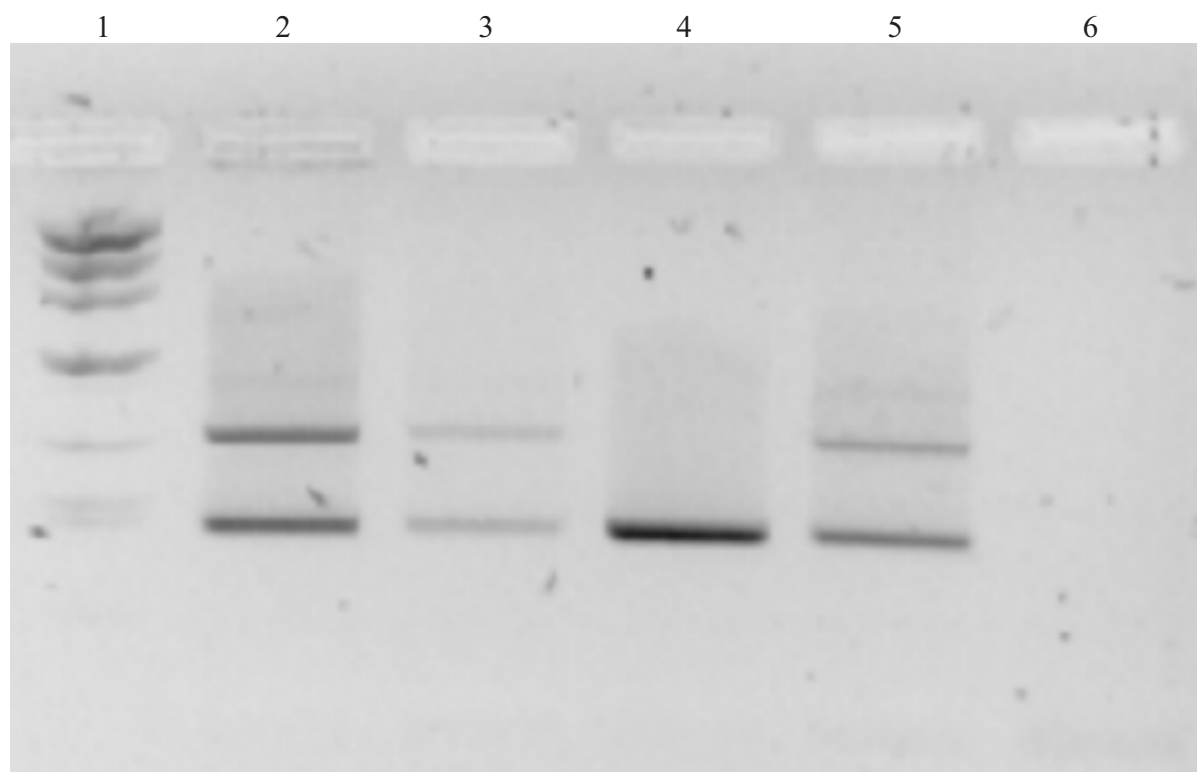

Fig. 1. Identification of CD carriers. From the left: line 1 molecular marker DRAMIX. Lines 2, 3 and 5 - CD carriers (both amplicons are present 249 bp and 436 bp); line 4 - normal animal (only lower band - 249 bp present); line 6 - negative control (PCR mix without DNA).

Table 1. Carriers of insertion within APOB gene causing Cholesterol Deficiency in sample of 27 Polish Holstein-Friesian bulls.

\begin{tabular}{cccc}
\hline DNA id & Bull name & Bull id number & Known CD carrier in pedigree \\
\hline 5288 & MAGENTA RED & US141304939 & MR BURNS - sire of dam \\
1461 & MOMENT & PL005100912369 & STORM - sire of dam \\
1963 & SALTOR ST & PL005106912998 & STORM - sire of sire \\
2955 & BARUBAR & PL005216372965 & MR BURNS - sire \\
5292 & PREDESTINE & US69177592 & GOLDWYN - sire of dam \\
2859 & JOSE & PL005137048444 & GOLDWYN - sire \\
2778 & INSERT ET & PL005142061698 & GOLDWYN - sire \\
5799 & nd & PL005252428817 & MAGNETA RED - sire \\
5808 & nd & PL005357031240 & MAGNETA RED - sire \\
\hline
\end{tabular}

nd - no data.

import of semen, and transfer of embryos enables rapid transmission of mutation across populations. The aim of this report was to find out whether carriers of CD occur in the population of Polish Holstein-Friesian bulls.

\section{Materials and Methods}

Twenty seven Polish Holstein-Friesian bulls were included in the analysis. Bull were selected as having in the pedigree world known carrier of CD (Maughlin Storm CANM000005457798). Genomic DNA was isolated from the half volume of one commercial semen straw or ear tissue samples using the NucleoMag 200 Purification Kit or NucleoSpin Tissue Kit according to the manufacturer's instructions (Macherey-Nagel,
Germany). All bulls were diagnosed by the test described by Menzi et al. (2016) by using 3 primers: forward common primer starting from wild sequence 5'GGTGACCATCCTCTCTCTGC3' and two primers discriminating wild sequence from mutant. Second wild reverse primer 5'AGTGGAACCCAGCTCCATTA3' ensured amplification of 249 bp, but mutant forward primer 5'CACCTTCCGCTATTCGAGAG3' starting from inserted LTR element produced larger amplicon of $436 \mathrm{bp}$. To obtain a 436 bp or 249 bp fragment of bovine APOB gene, the following PCR mix was used: 20x PCR Buffer, 10x dNTP mix (2 mM each), 10 pmol each of 3 PCR primers (synthesized by Genomed, Poland), 10x PCR Enhancer, $25 \mathrm{mM} \mathrm{MgCl}_{2}, 0.5 \mu \mathrm{Tfl}$ polymerase $(1 \mathrm{U} / \mu \mathrm{l})$, ca. $50 \mathrm{ng}$ of genomic DNA and $\mathrm{H}_{2} \mathrm{O}$ up to $25 \mu \mathrm{l}$ (all chemicals used in PCR mix except primers 
come from Epicenter, USA). The following thermal profile was used: pre-denaturation at $95^{\circ} \mathrm{C}$ for $3 \mathrm{~min}$ followed by 35 cycles of: $30 \mathrm{~s} 94^{\circ} \mathrm{C}, 30 \mathrm{~s} 60^{\circ} \mathrm{C}, 30$ $\mathrm{s} 72^{\circ} \mathrm{C}$ and finished by $5 \mathrm{~min}$ at $72^{\circ} \mathrm{C}$. Reactions were performed in a Mastercycler 5330 thermocycler (Eppendorf, Germany). Specificity and efficiency of PCR reaction products were analyzed in $1.5 \%$ agarose gel with ethidium bromide (EtBr), against DNA size marker DRAMIX (A\&A Biotechnology, Poland). In the electrophoresis, $1 \mathrm{x}$ TBE was used as a buffer (0.45 M Tris, $0.44 \mathrm{M} \mathrm{H}_{3} \mathrm{BO}_{3}, 0.5 \mathrm{M}$ EDTA). The electrophoresis was run for 35 min under voltage of $100 \mathrm{~V}$.

\section{Results and Discussion}

In Figure 1 typical picture of $\mathrm{CD}$ identification by PCR is shown. Carriers were identified as having two amplicons 436 and 249 bp in contrast to normal animals having only one band of $249 \mathrm{bp}$. Among 27 bulls which in pedigree files had known carriers of $C D$, 9 new carriers were found (Table 1). Kipp et al. (2015) estimated carrier frequency in German Holstein cattle as around $8.7 \%$ (among 3,400 screened). In another study, Schütz et al. (2016) found 12,5\% carriers among Holstein bull born between 2012 and 2015 in Germany. Results presented in our paper show that causal mutation for CD is already transmitted to Polish Holstein-Friesian cattle and, in our opinion, it is sufficient ground to take practical actions in order to avoid further spreading of cholesterol deficiency defect. They should rely on the same rule applied to previous genetic defects (Czarnik et al. 2007, Ruść et al. 2013). Uncontrolled spreading of CD will decrease the fertility of cows since the higher number of carriers increase the chance of producing recessive homozygotes. Fertility is currently one of the most important trait and therefore any factors leading to its deterioration should be limited. Taking into account that the population of Holstein-Friesian cows in Poland is approximately 2,4 million, the policy limiting the number of carriers of any genetic defects will give substantial savings in the future.

\section{References}

Czarnik U, Grzybowski G, Kamiński S, Prusak B, Zabolewicz T (2007) Effectiveness of a program aimed at the elimination of BLAD-carrier bulls from the Polish Holstein-Friesian cattle. J Appl Genet 48: 375-377.

Gross JJ, Schwinn AC, Schmitz-Hsu F, Menzi F, Drögemüller C, Albrecht C, Bruckmaier RM (2016) Rapid Communication: Cholesterol deficiency-associated APOB mutation impacts lipid metabolism in Holstein calves and breeding bulls. J Anim Sci 94: 1761-1766.

Kipp S, Segelke D, Schierenbeck S (2015) A new Holstein haplotype affecting calf survival. Proceedings of the 2015 Interbull Meeting, July 09-12, 2015, Orlando, Florida, USA. Interbull Bulletin 49: 49-53.

Menzi F, Besuchet-Schmutz N, Fragnière M, Hofstetter S, Jagannathan V, Mock T, Raemy A, Studer E, Mehinagic K, Regenscheit N, Meylan M, Schmitz-Hsu F, Drögemüller C (2016) A transposable element insertion in APOB causes cholesterol deficiency in Holstein cattle. Anim Genet 47(2): 253-257.

OMIA Database 001965-9913. Online Mendelian Inheritance of Animals. http://omia.angis.org.au/OMIA001965

Ruść A, Hering D, Puckowska P, Barcewicz M, Kaminski S (2013) Screening of Polish Holstein-Friesian bulls towards eradication of Complex Vertebral Malformation (CVM) carriers. Pol J Vet Sci 16: 579-581.

Schütz E, Wehrhahn C, Wanjek M, Bortfeld R, Wemheuer WE, Beck J, Brenig B (2016) The Holstein Friesian Lethal Haplotype 5 (HH5) Results from a Complete Deletion of TF B1M and Cholesterol Deficiency (CDH) from an ERV-(LTR) Insertion into the Coding Region of APOB. PLoS One 11: e0154602.

VanRaden P, Null D (2015) Holstein haplotype for cholesterol deficiency (HCD). Website of US Council of Dairy Cattle Breeding. https://www.cdcb.us/reference/changes/ HCD_inheritance.pdf

Young SG, Northey ST, McCarthy BJ (1988) Low plasma cholesterol levels caused by a short deletion in the apolipoprotein B gene. Science 241: 591-593. 